\title{
The Effect of Interval Training and Nettle Supplement on Glycemic Control and Blood Pressure in Men With Type 2 Diabetes
}

\author{
Akbar Ghalavand ${ }^{1}$, Pezhman Motamedi², Mojtaba Deleramnasab ${ }^{3 *}$, Mostafa Khodadoust ${ }^{4}$ \\ 'Ph.D Student, Department of Physical Education and Sports Science, Abadan Branch, Islamic Azad University, Abadan, \\ Iran \\ ${ }^{2}$ Assistant Professor, Department of Exercise Physiology, Faculty of Physical Education and Sport Sciences, Kharazmi \\ University, Tehran, Iran \\ ${ }^{3}$ Clinical Research Development Unit, Ami-Al-Momenin Hospital, Zabol University of Medical Sciences, Zabol, Iran \\ ${ }^{4} \mathrm{MSc}$, Department of Physical Education and Sports Science, Abadan Branch, Islamic Azad University, Abadan, Iran
}

\section{*Correspondence to}

Mojtaba Deleramnasab; Clinical Research Development Unit, Ami-Al-Momenin Hospital, Zabol University of Medical Sciences, Zabol, Iran.

Tel/Fax: +985432232166;

Email: delaramnasab@yahoo.com

Received September 4, 2016 Accepted February 18, 2017 Published online March 18, 2017

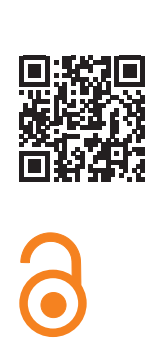

Please cite this article as follows: Ghalavand A, Motamedi P, Deleramnasab M, Khodadoust M. The effect of interval training and nettle supplement on glycemic control and blood pressure in men with type 2 diabetes Int J Basic Sci Med. 2017;2(1):3340. doi:10.15171/ ijbms.2017.08.

\begin{abstract}
Introduction: Exercise and herbal medicine are therapeutic approaches used to control blood sugar and blood pressure in diabetic patients. This study aimed to evaluate the effect of interval exercise and nettle supplements on blood glucose, and its role on blood pressure control in men with type 2 diabetes.

Methods: In this quasi experimental study, 40 men with type 2 diabetes aged 30-50 years old who were qualified based on our inclusion criteria were chosen and randomly divided into 4 groups (interval training [IT], nettle supplement [NS], nettle supplement combined with interval training $[\mathrm{IT}+\mathrm{NS}]$, and control). Blood pressure (BP) and fasting blood glucose (FBS) were measured at pre-test and post-test conditions. Paired sample t test and one-way analysis of variance (ANOVA) were used as statistical tests. Significance level was considered at $P \leq 0.05$. Results: Significant differences were detected regarding FBS levels in the three experimental groups in comparison with the control group $(P<0.05)$. Diastolic BP of the both IT and IT+NS groups was significantly different from the control group $(P<0.05)$. We also detected a significant difference in the diastolic BP between the IT+NS and the control group.

Conclusion: According to our results, aerobic IT and nettle supplementation are effective methods for controlling blood sugar and BP in patients with type 2 diabetes. We also showed that using the combination of the 2 methods was more effective than using the either method alone.

Keywords: Type 2 diabetes, Interval training, Nettle, Blood sugar, Blood pressure.
\end{abstract}

Management of cardiovascular problems in type 2 diabetes needs a coordinated system for controlling the risk of such events. This may have beneficial therapeutic effects in patients with diabetes. ${ }^{6}$

Hypertension is a common disease in diabetes affecting $20 \%-60 \%$ of the cases. Different prevalence rates of hypertension have been reported in Iranian diabetic patients. Three separate studies have reported the prevalence rates of $22.2 \%,{ }^{7} 35.5 \%,{ }^{8}$ and $45 \% .{ }^{9}$ Due to the proposed associations of high BP, especially systolic BP with the diabetes related organ dysfunctions of the eyes, kidney, and the heart, controlling BP

\footnotetext{
Copyright (C) 2017 The Author(s); Published by Zabol University of Medical Sciences. This is an open-access article distributed under the terms of the Creative Commons Attribution License (http://creativecommons.org/licenses/by/4.0), which permits unrestricted use, distribution, and reproduction in any medium, provided the original work is properly cited.
} 
can be beneficial in the clinical course of diabetic patients. ${ }^{2,10}$ Treatment of hypertension in patients with diabetes is essential to prevent cardiovascular complications such as stroke, coronary heart disease, etc. ${ }^{2}$ For achieving this purpose and facilitating treatment approaches, walking, exercising, weight control and diet modifications are crucial steps. ${ }^{5}$

Controlling blood sugar has been noted to lower the risk of cardiac abnormalities in diabetes. Congestive heart failure in diabetes (diabetic cardiomyopathy), multi-factor induced myocardial ischemia, hypertension, and myocardial cell dysfunction have been suggested to be results of chronic hyperglycemia. ${ }^{2}$ Regular exercise and increasing physical activity can help prevent and manage signs of metabolic syndrome. ${ }^{11}$ Exercise plays a positive role in people with type 2 diabetes through empowering the skeletal muscle for insulin independent glucose uptake. ${ }^{12}$ In addition, exercise can reduce diabetic complications such as low BP.,13 Multiple studies have been performed regarding the effect of exercise and sports activities in control of diabetes and BP. In accordance, one of the significant issues in this regard is the reducing effect of exercise on the BP of diabetic patients. ${ }^{14,15}$

There is much evidence to indicate that many medicinal plants can be useful for treating diabetes and preventing its complications. Nettle is the traditional term referring to a medicinal plant with scientific name of Urtica dioica from the family of Urticaceae. Nettle has traditionally been used to control blood sugar in Turkey and Morocco. In European countries, nettle is also used to reduce inflammation, and to treat rheumatoid arthritis. ${ }^{16}$ Some studies have also showed the effects of this plant on lowering the fasting blood sugar (FBS). Nettle leaves constitute several natural compounds (flavonoids, peptides and amines) that are known to have anti-diabetic effects. Some mechanisms including glycogenesis stimulation, block of potassium channels in the pancreatic beta cells, and interfering with the absorption of glucose from the intestinal wall have been mentioned underlying these anti-diabetic effects. ${ }^{17}$ Studies have shown positive effects of using decoction of nettle leaves or other plant parts either as infusion or oral use in diabetes. ${ }^{18,19}$ In vitro researches on animals, ${ }^{20}$ as well as some studies on humans ${ }^{16}$ have shown that nettle active compounds can be effective on BP, nevertheless, limited studies have been done on role of these in this area.

Due to lack of information surrounding the effects of exercise and consumption of nettle on BP and FBS levels in type II diabetic patients, this study aimed to evaluate the effects of eight weeks of interval training (IT) and use of nettle supplements (NSs) (individually and simultaneously) in controlling the FBS and BP in male participants with type 2 diabetes.

\section{Materials and Methods}

Subjects

In this interventional study, 40 men who suffered from type 2 diabetes were selected by purposive sampling method and were randomly divided into 4 groups (10 patients as IT, NS, combined IT+NS, and the control). The number of units and formulas to estimate the sample size was calculated according to previous reports (the following equation). ${ }^{5}$

$$
n=\frac{\left(z_{1-\frac{\alpha}{2}}+z_{1-\beta}\right)^{2}\left(s_{1}^{2}+s_{2}^{2}\right.}{\left(\bar{x}_{1}-\bar{x}_{2}\right)}
$$

\section{Inclusion Criteria}

Men with age of 30-50 years old diagnosed with type 2 diabetes, having FBS below $200 \mathrm{mg} / \mathrm{dL}$, normal BP, non-smoker, insulin-independent, without acute cardiovascular diseases, and respiratory disease and musculoskeletal problems were included in the study. Other inclusion criteria included a sedentary lifestyle, lack of regular physical activity during the past six months, and lack of recurrent hypoglycemia at rest or during exercise.

\section{Exclusion Criteria}

Missing of more than 2 consecutive sessions of the exercise, change of drug regimen, regular participation in exercise sessions other than the specified sports sessions in the case group, and regular exercise in the control group were among the exclusion criteria.

\section{Measurements}

After confirmation of the disease and agreement of the center physician to perform exercise, participants were thoroughly informed about the purposes of the study, and were trained in connection with the procedure (written and verbally). After obtaining written consent, basal measurements were taken, and interventional exercise was conducted under the researcher's supervision in the case group for eight weeks. The parameters were re-measured 2 days after the exercise session and nettle administration.

\section{Anthropometric Indicators}

In this study, standing height of the subjects without shoes was measured by a stadiometer. Their weight was measured by SECA scales with the least possible clothing. In order to calculate the body mass index, weight (kilograms) was divided by the square of the height (meters). As previously described, we applied the multicomponent predication equation and skin-fold thicknesses to extrapolate the body fat percentage (PBF) using. The Lafayette Caliper (Model 01127) instrument was used for obtaining skin-fold thicknesses at three different locations including abdomen, thigh, and the chest. We performed all the mentioned assessments twice. The measurements were done on the right side of the body while the patients were standing and breathing normally. ${ }^{21}$ The equation for calculating body density is as follows:

Body Density $=1.10938-(0.0008267 \times$ sum of chest, abdomen and thigh skinfolds in $\mathrm{mm})+(0.0000016 \times$ square 
of the sum of chest, abdomen and thigh) - (0.0002574 $\times$ age)

Percentage of Body Fat $=(4.95 / \mathrm{BD}-4.5) \times 100$

\section{Blood Pressure}

Systolic and diastolic BP were measured in compliance with standard criteria. ${ }^{22}$ This was in an upright position following 15 minutes of rest before using a Hansen mercury sphygmomanometer (made in German) and Littmann stethoscope (made in USA). Rockport test was used to measure aerobic capacity $\left(\mathrm{VO}_{2} \max \right)$ in the patients. ${ }^{23}$

\section{Blood Glucose}

In this study, pre-test FBS was measured after 10-12 hours of fasting at the day before starting the training programs. Blood samples $(5 \mathrm{~mL})$ were taken with a syringe based on standard procedure in the sitting position. Post-test FBS was measured 2 days after the last session of exercise using the same protocol. For determining the values, blood samples were centrifuged within 30-45 minutes after obtaining and FBS was measured by a standard biochemistry autoanalyzer and Pars Azmoon kit (made in Iran).

\section{Exercise Training}

In this quasi-experimental study, IT as the intervention (in IT and NS + IT groups) consisted of "running" in compliance with the recommendations of the American Diabetes Association (ADA) ${ }^{15}$ and American College of Sports Medicine (ACSM). ${ }^{15,24}$ The IT group was safely performed under supervision of the researcher. At the beginning of each session, aerobic exercises (2 steps 3 minutes fast walk and jogging) and then static stretching were performed as warm up. ${ }^{5}$ The main exercise program was designed according to the exercise recommendations for diabetics (Table 1). ${ }^{1524}$ Training intensity was based on subjects' heart rate reserve and was controlled by applying the Karvonen method (20). After completing the basic training, fast walking and stretching for 5 minutes, cooling down was performed. To prevent possible risks during exercise, a nurse attended practice sessions and referred the patients to the doctor in case of any problems. It was also advised that patients have sweet snacks to prevent possible hypoglycemia. Before each training session, blood glucose (digital glucometer GC model) and BP (digital sphygmomanometer, BM1004) were measured.
Nettle Supplementation

In the experimental groups (NS and NS + IT), Nettle supplements were consumed consumed 15 minutes before 3 main meals (breakfast, lunch and dinner) for 8 weeks. Urtica dioica dose was calculated based on previous studies $(10 \mathrm{~g} / \mathrm{d})$ which was divided into 3 parts. ${ }^{16,25}$

\section{Statistical Methods}

Normality of the data was checked using the Kolmogorov-Smirnov and Levene test of homogeneity. Paired samples $t$ test and one-way analysis of variance (ANOVA) were used to compare pre-test and post-test FBS and BP between the groups and within-groups. All results are shown as mean \pm SD and $P$ values $\leq 0.05$ were considered statistically significant.

\section{Results}

According to the findings, no significant differences were seen in the demographic characteristics (age, weight, height, body mass index, body fat percent, aerobic capacity and the time from the diagnosis of diabetes) between the groups at pre-test (Table 2).

Comparison of pre-test and post-test data showed a significant reduction of FBS in all 3 experimental groups $(P<0.001)$. Systolic BP decreased significantly in the IT group $(P<0.05)$ and IT+NS group $(P<0.001)$. A significant decrease in diastolic BP was also observed between groups of IT $(P<0.05)$, NS $(P<0.05)$, and IT+NS $(P<0.01)$ (Table 3$)$.

One-way ANOVA test showed significant differences for post-test FBS $(P<0.001)$, systolic BP $(P<0.001)$ and diastolic BP $(P<0.05)$ between the studied groups (Table 4$)$. Post hoc Tukey test results showed a significant difference in levels of FBS in the intervention groups compared to the control group $(P<0.01)$. However, there was no significant difference between the experimental groups $(P<0.05$, Table 5). A significant difference in systolic BP changes was seen comparing either IT or IT+NS groups compared to the control group $(P<0.05)$. Diastolic BP was also significantly different between the IT+NS group and the control group $(P<0.05)$.

\section{Discussion}

Fasting Blood Glucose

Our results showed a significant decrease in FBS ratio as

Table 1. Interval Training Program in Type 2 Diabetes Patients

\begin{tabular}{|c|c|c|c|c|c|}
\hline Week & $\begin{array}{c}\text { No. of Sessions/ } \\
\text { Week }\end{array}$ & No. of Cycles & $\begin{array}{l}\text { Interval Activity Time } \\
\text { (min) }\end{array}$ & $\begin{array}{c}\text { Intensity (Percentage of } \\
\text { Heart Rate Reserve) }\end{array}$ & $\begin{array}{c}\text { Rest to Practice } \\
\text { Ratio }\end{array}$ \\
\hline 1 & 3 & 2 & 5 & $50 \%-60 \%$ & $1: 1$ \\
\hline 2 & 3 & 3 & 5 & $50 \%-60 \%$ & $1: 1$ \\
\hline 3 & 3 & 3 & 5 & $50 \%-60 \%$ & $1: 1$ \\
\hline 4 & 3 & 4 & 5 & $50 \%-60 \%$ & $1: 1$ \\
\hline 5 & 3 & 4 & 5 & $60 \%-70 \%$ & $1: 1$ \\
\hline 6 & 3 & 5 & 5 & $60 \%-70 \%$ & $1: 1$ \\
\hline 7 & 3 & 5 & 5 & $60 \%-70 \%$ & $1: 1$ \\
\hline 8 & 3 & 6 & 5 & $60 \%-70 \%$ & $1: 1$ \\
\hline
\end{tabular}


Table 2. Demographic, Clinical and Laboratory Characteristics of Subjects With Type 2 Diabetes

\begin{tabular}{|c|c|c|c|c|c|c|}
\hline & IT & NS & $\mathrm{IT}+\mathrm{NS}$ & Control & $\boldsymbol{F}$ & $\boldsymbol{P}$ \\
\hline Age (y) & $41.80 \pm 3.99$ & $44.30 \pm 2.63$ & $40.40 \pm 4.70$ & $41.80 \pm 3.94$ & 1.745 & 0.175 \\
\hline Height $(\mathrm{cm})$ & $170.16 \pm 5.51$ & $169.17 \pm 6.25$ & $167.35 \pm 5.44$ & $168.43 \pm 6.54$ & 0.397 & 0.756 \\
\hline Weight (kg) & $77.27 \pm 4.10$ & $75.53 \pm 5.45$ & $76.13 \pm 6.01$ & $78.71 \pm 7.51$ & 0.564 & 0.642 \\
\hline BMI $\left(\mathrm{kg} / \mathrm{m}^{2}\right)$ & $26.72 \pm 1.71$ & $26.44 \pm 2.13$ & $27.15 \pm 0.95$ & $27.70 \pm 1.41$ & 1.166 & 0.336 \\
\hline $\mathrm{VO}_{2} \max (\mathrm{mL} / \mathrm{kg} / \mathrm{min})$ & $33.31 \pm 4.58$ & $31.65 \pm 5.69$ & $31.87 \pm 2.83$ & $32.22 \pm 3.67$ & 0.052 & 0.984 \\
\hline Time from diabetes diagnosis (y) & $2.80 \pm 1.55$ & $2.40 \pm 1.35$ & $2.20 \pm 1.40$ & $3.30 \pm 1.16$ & 1.254 & 0.305 \\
\hline FBS $(\mathrm{mg} / \mathrm{dL})$ & $151.60 \pm 6.59$ & $159.00 \pm 9.10$ & $158.60 \pm 11.30$ & $151.70 \pm 5.58$ & 1.375 & 0.266 \\
\hline Systolic BP (mm Hg) & $135.40 \pm 5.25$ & $136.60 \pm 3.69$ & $137.30 \pm 3.95$ & $134.50 \pm 5.48$ & 0.714 & 0.550 \\
\hline Diastolic BP (mm Hg) & $85.50 \pm 4.74$ & $85.10 \pm 3.14$ & $86.60 \pm 3.13$ & $84.60 \pm 3.20$ & 0.551 & 0.650 \\
\hline
\end{tabular}

Abbreviations: IT, interval training; NS, nettle supplemented; BMI, body mass index; FBS, fasting blood sugar; BP, blood pressure.

Table 3. Comparison of Pre-test and Post-test Values of FBS, and systolic and diastolic BPs in 3 Experimental and Control Groups

\begin{tabular}{|c|c|c|c|c|c|}
\hline Variable & Group & Pre-test & Post-test & $t$ & $P$ \\
\hline \multirow{4}{*}{ FBS (mg/dL) } & IT & $151.60 \pm 6.59$ & $136.30 \pm 6.15$ & 14.81 & $0.000^{c}$ \\
\hline & NS & $159.00 \pm 9.10$ & $146.80 \pm 8.73$ & 12.37 & $0.000^{\mathrm{c}}$ \\
\hline & $\mathrm{IT}+\mathrm{NS}$ & $158.60 \pm 11.30$ & $142.40 \pm 16.09$ & 5.922 & $0.000^{c}$ \\
\hline & Control & $151.70 \pm 5.58$ & $149.50 \pm 10.64$ & 0.628 & 0.545 \\
\hline \multirow{4}{*}{ Systolic BP (mm Hg) } & IT & $135.40 \pm 5.25$ & $130.30 \pm 4.88$ & 3.104 & $0.013^{\mathrm{a}}$ \\
\hline & NS & $136.60 \pm 3.69$ & $133.50 \pm 4.79$ & 1.718 & 0.120 \\
\hline & $\mathrm{IT}+\mathrm{NS}$ & $137.30 \pm 3.95$ & $127.50 \pm 6.49$ & 5.838 & $0.000^{c}$ \\
\hline & Control & $134.50 \pm 5.48$ & $138.30 \pm 5.68$ & -1.610 & 0.142 \\
\hline \multirow{4}{*}{ Diastolic BP (mm Hg) } & $\mathrm{IT}$ & $85.50 \pm 4.74$ & $82.20 \pm 4.24$ & 2.262 & $0.028^{a}$ \\
\hline & NS & $85.10 \pm 3.14$ & $83.10 \pm 3.70$ & 2.449 & $0.037^{\mathrm{a}}$ \\
\hline & $\mathrm{IT}+\mathrm{NS}$ & $86.60 \pm 3.13$ & $83.00 \pm 2.75$ & 3.959 & $0.003^{b}$ \\
\hline & Control & $84.60 \pm 3.20$ & $84.50 \pm 2.99$ & 0.218 & 0.832 \\
\hline
\end{tabular}

Abbreviations: IT, interval training; NS, nettle supplemented; FBS, fasting blood sugar; BP, blood pressure.

a Significance level $P<0.05$; ${ }^{\text {b }}$ Significance level $P<0.01$; ${ }^{c}$ Significance level $P<0.001$.

Table 4. Mean Differences of FBS, Systolic and Diastolic BPs Between Experimental And Control Groups.

\begin{tabular}{|c|c|c|c|c|c|c|}
\hline Variable & IT & NS & IT+NS & Control & $\boldsymbol{F}$ & $\boldsymbol{P}$ \\
\hline $\mathrm{FBS}(\mathrm{mg} / \mathrm{dL})$ & $-15.30 \pm 3.27$ & $-12.20 \pm 3.12$ & $-16.20 \pm 8.65$ & $-2.20 \pm 11.07$ & 7.556 & $0.000^{b}$ \\
\hline Systolic BP (mm Hg) & $-5.10 \pm 5.20$ & $-3.10 \pm 5.71$ & $-9.80 \pm 5.31$ & $3.80 \pm 7.47$ & 8.895 & $0.000^{\mathrm{b}}$ \\
\hline Diastolic BP (mm Hg) & $-3.30 \pm 3.97$ & $-2.00 \pm 2.58$ & $-3.60 \pm 2.88$ & $-0.10 \pm 1.45$ & 3.091 & $0.039^{\mathrm{a}}$ \\
\hline
\end{tabular}

Abbreviations: IT, interval training; NS, nettle supplemented; FBS, fasting blood sugar; BP, blood pressure.

a Significance level $P<0.05 ;{ }^{b}$ Significance level $P<0.001$.

$10.08 \%, 7.67 \%$, and $10.40 \%$ reduction in the IT group, the NS group, and the IT+NS group respectively. The difference was statistically significant between the intervention groups and the control group. However, this was no statistical significance when comparing between treatment groups. Our findings on the effect of exercise on blood sugar were similar with previous findings. ${ }^{5,21,26-30}$ Nevertheless, results of a study by Karstoft et al differed from our findings. ${ }^{31}$ These differences may be due to the participant's characteristics. The study of Karstoft et al consisted of elderly patients (over 57 years) with high BMI $(29 \mathrm{~kg} /$ $\mathrm{m}^{2}$ ) which could lead to muscle weakness and the failing to exercise with desired intensity. Furthermore, their research protocol included four months of walking, while running aerobic exercise was not used in the recent study. Physical activity has a positive effect on insulin resistance in patients with type 2 diabetes, and exercise can decrease insulin resistance. ${ }^{32,33}$ The accumulation of free fatty ac- ids in muscle cells disrupts the transmission of glucose transferase-4 (GLUT4) to cell surface membrane. Aerobic exercise may increase the oxidation of fatty acids, and prohibit their accumulation in muscle cells. ${ }^{33}$ Increased capillary density, increased sensitivity of insulin receptors, a change in the composition of phospholipid sarcolemma, increased glycogen synthase enzyme activity and increased enzyme oxidative activity are also important factors in lowering blood sugar. ${ }^{34}$ Increased insulin action and increased insulin signals are other regulating factors of glucose metabolism. ${ }^{35,36}$

Our observation regarding significant decreases in blood sugar levels in the intervention groups were similar to the findings of other studies, ${ }^{37-40}$ reporting the efficacy of nettle administration on glycemic control. In spite of this, some studies showed no positive correlation between the use of nettle and declining of blood sugar. ${ }^{41,42}$

Studies have shown the positive effect of the injectable or 
Table 5. Results of Post Hoc Tukey Test

\begin{tabular}{llccc}
\hline \multirow{2}{*}{ Group I } & \multirow{2}{*}{ Group J } & FBS & Systolic BP & Diastolic BP \\
\cline { 3 - 5 } & & $\boldsymbol{P}$ & $\boldsymbol{P}$ & $\boldsymbol{P}$ \\
\hline IT & NS & 0.784 & 0.877 & 0.742 \\
IT & IT+NS & 0.993 & 0.311 & 0.995 \\
IT & Control & $0.002^{\mathrm{a}}$ & $0.011^{\mathrm{a}}$ & 0.077 \\
NS & IT+NS & 0.623 & 0.077 & 0.601 \\
NS & Control & $0.022^{\mathrm{a}}$ & 0.065 & 0.458 \\
IT+NS & Control & $0.001^{\mathrm{a}}$ & $0.000^{\mathrm{b}}$ & $0.046^{\mathrm{a}}$ \\
\hline
\end{tabular}

Abbreviations: IT, interval training; NS, nettle supplemented; FBS, fasting blood sugar; BP, blood pressure.

a Significance level $P<0.05 ;{ }^{\text {b }}$ Significance level $P<0.001$.

oral forms of the decoction of nettle leaves or other plant parts on diabetes. ${ }^{18,19}$ Animal studies have shown that nettle active compounds can increase insulin levels in natural diabetes and diabetes caused by streptozotocin. ${ }^{39,43,44}$ Three possible mechanisms have been suggested for the blood glucose lowering effects of Nettle by Fakhraee and colleagues. ${ }^{19}$ These suggestions include $(a)$ enhancing glucose uptake by muscles through increasing formation of permeable pores, $(b)$ stimulating the release of insulin from pancreatic beta cells, and $(c)$ inhibiting the activity of alpha-amylase, a carbohydrate hydrolysis inhibitor, which ultimately leads to modulation of blood sugar in type 2 diabetes.

Several natural compounds are present in the leaves of stinging nettle (flavonoids, peptides and amines). Some of them are known to present anti-diabetic effects. The combined effect of the above mentioned mechanisms include stimulation of glycogenesis, blocking of potassium channels in the pancreatic beta cells, and interference with the absorption of glucose from the intestinal wall. ${ }^{17}$ In a study on the effect of nettle on lowering blood glucose by Kavalalı et al, protective effects of nettle were shown against histologic deterioration of pancreatic cells in rat models of streptozotocin-induced diabetes. ${ }^{38}$ Bnouham et al also reported the effect of nettle in reducing blood sugar by decreasing the intestinal absorption of glucose. ${ }^{37}$ We noticed a slight difference of blood sugar between the 2 experimental groups; IT and IT+NS. In accordance, Dabagh et al showed that alternation magnitude of blood glucose level was higher in the group with combination of nettle and exercise training compared to separate individual groups. This difference was attributed to the cumulative effect of aerobic training and nettle. ${ }^{45}$ Low magnitude difference between the 2 groups observed in the present study may be explained by more energy cost in IT, conducted in our study, compared to continuous training performed in the above-mentioned studies.

\section{Blood Pressure}

Significant reductions in systolic BP as high as 3.69\%, $2.21 \%$, and $7.14 \%$ were recorded in IT, NS, and IT+NS groups respectively. In the control group, a non-significant increase $(2.97 \%)$ was observed in the level of systolic $\mathrm{BP}$. When comparing the changes between the groups, significant differences were seen between the interven- tion groups (IT and IT+NS) and the control group. A significant decrease in the systolic BP was consistent with the findings of some previous reports. ${ }^{1,21,46}$ On the other hand, Shenoy et $\mathrm{al}^{34}$ reported no significant differences in systolic BP after sixteen weeks of aerobic training. This may be due to the differences between the subjects participated in the recent study with our study, or the effect of nutritional intervention in study of Shenoy et al.

A significant decrease in diastolic BP was also detected as $3.74 \%$ in the IT group, $2.33 \%$ in NS group, and $4.10 \%$ in the IT+NS group. In the control group, diastolic BP showed an insignificant reduction of $0.10 \%$. Significant differences were observed between IT+NS group and the control group. In line with this, Bagheri et $\mathrm{al}^{21}$ reported a significant reduction in diastolic BP which is similar to the findings of the present study. In another study by Shenoy et al, ${ }^{34}$ however, aerobic exercise did no inflict any significant difference in diastolic BP, while Ezema et $\mathrm{al}^{46}$ showed a significant decrease in diastolic BP. Also, Yavari et $\mathrm{al}^{147}$ reported a significant increase in diastolic BP after a period of aerobic exercise, however, no significant difference was reported between the exercise and control groups. In the present study, a significant difference was observed between the IT group and the control group regarding BP. The reason for these different results may root in different exercise protocols, and patients' characteristics. In addition, the role of nutrition, as a limitation of our study, should be noted. Another explanation that could be mentioned is the use of antihypertensive drugs by individuals in previous studies. ${ }^{1}$ However, we managed this confounding effect by excluding patients who used these therapeutics.

Figueira et al reviewed the effect of exercise on BP in patients with type 2 diabetes. Based on this, high-intensity exercise was effective in lowering BP in patients with type 2 diabetes, especially if the exercise program sessions exceeded $150 \mathrm{~min} / \mathrm{wk} .{ }^{10}$ Furthermore, regular exercise has been introduced as a therapeutic approach in improving $\mathrm{BP} .^{48}$ Interestingly, maintaining systolic BP at $140 \mathrm{~mm} \mathrm{Hg}$, depending on age of the patients, resulted in a $28 \%-44 \%$ and 20\%-35\% decrease in the incidence of strokes and ischemic heart disease respectively. ${ }^{49}$ Credible evidences suggest that exercise is a substantial factor in improving endothelial function, vascular expandability, left ventricular diastolic function, and ventricular stroke volume in lowering $\mathrm{BP}^{47,50}$

In a clinical trial study to evaluate the effect of Urtica dioica on BP in diabetic patients, Kianbakht e $\mathrm{al}^{51}$ reported no significant differences in systolic and diastolic BP following 3 months of the agent administration. In another study, Namazi et al administered 8 weeks of nettle with dose of $100 \mathrm{mg} / \mathrm{d}$ for patients with type 2 diabetes. A significant difference was seen in systolic BP between the 2 groups, but no significant difference was reported in diastolic BP. ${ }^{16}$ These are inconsistent with the findings of our study. This can be due to the differences in administration methods of nettle.

Pilot studies have shown that nettle causes vasodilatation 
and consequently reduces $\mathrm{BP}$ through its effects on the nitric oxide pathway. ${ }^{52}$ Also, Legssyer et al showed that nettle reduced both BP and heart rate in rats. ${ }^{53}$ In patients with type 2 diabetes, essential hypertension is associated with insulin resistance, increased insulin secretion, and sensitivity by acting on acetylcholine which leads to the expansion of blood vessels and lowering BP. ${ }^{54}$ Due to the presence of a combination of flavonoids in nettle, it is likely that herbs can lower systolic BP by mentioned mechanisms. ${ }^{55}$

Significant differences in BP were not observed between the experimental groups, however, considering bigger changes in groups of IT+NS respective to either IT or NS groups, it can be said that the combination of these interventions is more effective in controlling BP in type 2 diabetic patients. This observation may indicate a synergistic effect of the 2 methods (IT+NS) probably through adjustment on cardiovascular system by diuretic and natriuretic effects of nettle. ${ }^{47}$ In previous studies, diuretics effects of Urtica dioica, and its beneficial role on renal function have been reported. ${ }^{56,57}$ Finally, combined IT+NS can improve cardiovascular function in type 2 diabetic patients. It is recommended to investigate the role of these potential interventions on the clinical course of diabetes in more details.

\section{Conclusion}

Overall, the findings of this study indicated the positive effect of IT and nettle consumption on the improvement of glycemic control and BP in men with type II diabetes. Comparing the three experimental groups, no significant difference was seen regarding BP, however, simultaneous use of both interventions (IT and NS) seemed to be more effective than individual interventions.

\section{Ethical Approval}

Our study was approved by the ethics committee of Abadan Branch, Islamic Azad University (Grant No. 1140).

\section{Acknowledgements}

This project was registered in Abadan Branch, Islamic Azad University. The authors would like to thank all who cooperated in this research.

\section{References}

1. Yan H, Prista A, Ranadive SM, et al. Effect of aerobic training on glucose control and blood pressure in T2DDM East African males. ISRN Endocrinol. 2014;2014:864897. doi:10.1155/2014/864897.

2. Emdin CA, Rahimi K, Neal B, Callender T, Perkovic V, Patel A. Blood pressure lowering in type 2 diabetes: a systematic review and meta-analysis. JAMA. 2015;313(6):603-615. doi:10.1001/jama.2014.18574.

3. Mirfeizi M, Mehdizadeh Tourzani Z, Mirfeizi S, Asghari Jafarabadi M, Rezvani H, Shoghi M. Effects of cinnamon on controlling blood glucose and lipids in patients with type II diabetes mellitus: a double blind, randomized clinical trial (Persian). Medical Journal of Mashhad University of
Medical Sciences. 2014;57(3):533-541.

4. Sardar MA, Gaeini A, Ramezani J. The effect of 8-weeks of regular physical activity on blood glucose, body mass index, maximal oxygen uptake (Vo2max) and risk factors cardiovascular diseases in patients with type of 1 diabetes mellitus. Iranian Journal of Endocrinology and Metabolism. 2008;10(2):91-97.

5. Ghalavand A, Shakeriyan S, Monazamnezhad A, Delaramnasab M. The effect of resistance training on cardio-metabolic factors in males with type 2 diabetes. Jundishapur J Chronic Dis Care. 2014;3(4):e23346. doi:10.5812/jjcdc.23346.

6. Azadbakht L, Rashidpourfard N, Karimi M, et al. The dietary approaches to stop hypertention (DASH) and cardiovascular risk factors among type 2 diabetic patients (Persian). Health Syst Res. 2012;7(3):347-352.

7. Meraci M, Feizi A, Bagher Nejad M. Investigating the prevalence of high blood pressure, type 2 diabetes mellitus and related risk factors according to a large general study in Isfahan- using multivariate logistic regression model (Persian). J Health Syst Res. 2013;8(2):193-203.

8. Masoumi M, Saeidi MR, Piri F, Abdoli GR. Epidemiological evaluation of coronary artery disease (CAD) in Patients referred to cardiovascular centers of Kermanshah (20012002) (Persian). J Kermanshah Univ Med Sci. 2004;8(2).

9. Teimouri A, Amini M. The quality of care and treatment in diabetic patients newly diagnosed by screening. Iranian Journal of Endocrinology \& Metabolism. 2007;8(4):300309.

10. Figueira FR, Umpierre D, Cureau FV, et al. Association between physical activity advice only or structured exercise training with blood pressure levels in patients with type 2 diabetes: a systematic review and meta-analysis. Sports Med. 2014;44(11):1557-1572. doi:10.1007/s40279-0140226-2.

11. Hajihasani A, Bahrpeyma F, Bakhtiari A, Tagikhani M. Effects of eccentric and concentric exercises on some blood biochemical parameters in patients with type 2 diabetes (Persian). Koomesh. 2012;13(3):338-344.

12. Tadibi V, Rahimi M, Bayat Z. The effectiveness of 8-week aerobic exercise and drug modification on metabolic indices in women with type 2 diabetes (Persian). Journal of Kermanshah University of Medical Sciences. 2012;16(5):380-390.

13. Morvan E, Lima NEA, Machi JF, et al. Metabolic, hemodynamic and structural adjustments to low intensity exercise training in a metabolic syndrome model. Cardiovasc Diabetol. 2013;12(1):89. doi:10.1186/14752840-12-89.

14. Kokkinos PF, Narayan P, Papademetriou V. Exercise as hypertension therapy. Cardiol Clin. 2001;19(3):507-516. doi:10.1016/S0733-8651(05)70232-0.

15. Standards of medical care in diabetes-2012. Diabetes Care. 2012;35:S11-S63. doi:10.2337/dc12-s011.

16. Namazi N, Bahrami A. Effect of hydro-alcoholic nettle extract on lipid profiles and blood pressure in type 2 diabetes patients. Iran J Endocrinol Metab. 2012;13(5):449458.

17. Mobasseri M, Bahrami A, Zargami N, et al. Effect of total extract of Urtica dioica on insulin and C-peptide secretion from rat (RIN5F) pancreatic $\beta$ cells and glucose utilization by human muscle cells. Iran J Endocrinol Metab. 2009;11(6):721-727. 
18. Hasani-Ranjbar S, Larijani B, Abdollahi M. A systematic review of Iranian medicinal plants useful in diabetes mellitus. Arch Med Sci. 2008;4(3):285-292.

19. Fakhraee SH, Jouyandeh Z, Mehri A, Larijani B, Hasaniranjbar S. Systematic review on the effectiveness and safety of nettle herb in treating diabetes. Iranian Journal of Diabetes and Lipid Disorders. 2012;12(6):507-523.

20. Chrubasik JE, Roufogalis BD, Wagner H, Chrubasik S. A comprehensive review on the stinging nettle effect and efficacy profiles. Part II: urticae radix. Phytomedicine. 2007;14(7-8):568-579. doi: 10.1016/j.phymed.2007.03.014.

21. Bagheri A, Ghalavand A, Salvand G, Kamounzadeh A, Akram M. Effects of 8-week aerobic exercise on blood glycemic indexes and anthropometric of patients with type 2 diabetes in the Dezful. Journal of Scientific Research and Development. 2015;2(1):89-94.

22. Pescatello L, Franklin B, Fagard R, Farquhar W, Kelley G, Ray C. Exercise and hypertension: American College of Sports Medicine Position Stand. Med Sci Sports Exerc. 2004;36(3):533-553

23. Hoffman J. Norms for Fitness, Performance, and Health. Human Kinetics; 2006.

24. Balducci S, Sacchetti M, Haxhi J, et al. Physical exercise as therapy for type 2 diabetes mellitus. Diabetes Metab Res Rev. 2014;30(S1):13-23. doi:10.1002/dmrr.2514.

25. Barnes J, Anderson LA, Phillipson JD, Newall CA. Herbal Medicines. London: Pharmaceutical Press; 2007.

26. Bacchi E, Negri C, Zanolin ME, et al. Metabolic effects of aerobic training and resistance training in type 2 diabetic subjects a randomized controlled trial (the RAED2 study). Diabetes Care. 2012;35(4):676-682. doi:10.2337/dc111655.

27. Tamura Y, Tanaka Y, Sato F, et al. Effects of diet and exercise on muscle and liver intracellular lipid contents and insulin sensitivity in type 2 diabetic patients. J Clin Endocrinol Metab. 2005;90(6):3191-3196. doi:10.1210/jc.2004-1959.

28. Misra A, Alappan NK, Vikram NK, et al. Effect of supervised progressive resistance-exercise training protocol on insulin sensitivity, glycemia, lipids, and body composition in Asian Indians with type 2 diabetes. Diabetes Care. 2008;31(7):1282-1287. doi:10.2337/dc07-2316.

29. Castaneda C, Layne JE, Munoz-Orians L, et al. A randomized controlled trial of resistance exercise training to improve glycemic control in older adults with type 2 diabetes. Diabetes care. 2002;25(12):2335-2341. doi:10.2337/diacare.25.12.2335.

30. Ghalavand A, Shakeriyan S, Monazamnezhad A, Dadvar N, Heidarnezhad M, Delaramnasab M. The effects of aerobic training on blood glycemic control and plasma lipid profile in men with type 2 diabetes. SYLWAN. 2014;158(6):1-10.

31. Karstoft K, Winding K, Knudsen SH, et al. The effects of free-living interval-walking training on glycemic control, body composition, and physical fitness in type 2 diabetic patients: a randomized, controlled trial. Diabetes Care. 2013;36(2):228-236. doi: 10.2337/dc12-0658.

32. Shavandi N, Shahrjerdi S, Sheikh Hoseini R, Ghorbani A. The effect of strengthening exercises on metabolic factors, quality of life and mental health in women with type 2 diabetes. Iran J Endocrinol Metab. 2010;12(3):222-230.

33. Rahimi N, Marandi SM, Kargarfard M. The effects of eightweek aquatic training on selected physiological factors and blood sugar in patients with type 2 diabetes (Persian). Journal of Isfahan Medical School. 2011;29(142):722-732.

34. Shenoy S, Arora E, Jaspal S. Effects of progressive resistance training and aerobic exercise on type 2 diabetics in Indian population. Int J Diabetes Metab. 2009;17:27-30.

35. Teixeira-Lemos E, Nunes S, Teixeira F, Reis F. Regular physical exercise training assists in preventing type 2 diabetes development: focus on its antioxidant and antiinflammatory properties. Cardiovasc Diabetol. 2011;28:1012. doi: 10.1186/1475-2840-10-12.

36. Wang Y, Simar D, Fiatarone MA. Adaptations to exercise training within skeletal muscle in adults with type 2 diabetes or impaired glucose tolerance: a systematic review. Diabetes Metab Res Rev. 2009;25:13-40. doi:10.1002/ dmrr.928.

37. Bnouham M, Merhfour F-Z, Ziyyat A, Mekhfi H, Aziz M, Legssyer A. Antihyperglycemic activity of the aqueous extract of Urtica dioica. Fitoterapia. 2003;74(7):677-681. doi:10.1016/S0367-326X(03)00182-5.

38. Kavalalı G, Tuncel H, Göksel S, Hatemi H. Hypoglycemic activity of Urtica pilulifera in streptozotocin-diabetic rats. J Ethnopharmacol. 2003;84(2):241-245. doi:10.1016/S03788741(02)00315-X.

39. Qujeq D, Davary S, Moazzi Z, Mahjoub S. Effect of Urtica dioica leaf extract on activities of nucleoside diphosphate kinase and acetyl coenzyme, a carboxylase, in normal and hyperglycemic rats. Afr J Pharm Pharmacol. 2011;5(6):792796. doi:10.5897/AJPP11.246

40. Rezaei AT, Minaii Zangii B, Latifpour M. Protective effects of Urtica dioica extract on the damage of rat small intestinal mucosa caused by diabetes. Journal of Babol University of MedicaL Sciences. 2012;14(3):31-37.

41. Swanston-Flatt SK, Day C, Flatt PR, Gould B, Bailey C. Glycaemic effects of traditional European plant treatments for diabetes. Studies in normal and streptozotocin diabetic mice. Diabetes Res. 1989;10(2):69-73.

42. Roman RR, Alarcon-Aguilar F, Lara-Lemus A, FloresSaenz J. Hypoglycemic effect of plants used in Mexico as antidiabetics. Arch Med Res. 1991;23(1):59-64.

43. Das M, Sarma B, Rokeya B, et al. Antihyperglycemic and antihyperlipidemic activity of Urtica dioica on type 2 diabetic model rats. J Diabetol. 2011;2(2):1-6.

44. Farzami B, Ahmadvand D, Vardasbi S, Majin F, Khaghani S. Induction of insulin secretion by a component of Urtica dioica leave extract in perifused Islets of Langerhans and its in vivo effects in normal and streptozotocin diabetic rats. J Ethnopharmacol. 2003;89(1):47-53. doi:10.1016/S03788741(03)00220-4.

45. Dabagh S, Nikbakht M. Glycemic control by exercise and Urtica dioica supplements in men with type 2 diabetes. Jundishapur J Chronic Dis Care. 2016;5(1):e31745. doi:10.17795/jjcdc-31745.

46. Ezema CI, Onwunali A, Lamina S, Ezugwu U, Amaeze A, Nwankwo M. Blood glucose response to aerobic exercise training programme among patients with type 2 diabetes mellitus at the University of Nigeria Teaching Hospital, Enugu South-East, Nigeria. Int J Diabetes Dev Ctries. 2014;17(2):54. doi:10.4103/1118-8561.134476

47. Yavari A, Najafipoor F, Aliasgarzadeh A, Niafar M, Mobasseri M. Effect of aerobic exercise, resistance traning or combined traning on glycemic control and cardiovascular risk factor in patients with type 2 diabetes. Biol Sport. 2012;29(2):135-143. doi:10.5604/20831862.990466.

48. Weibert R. Textbook of Therapeutics, Drugs and Diseases Management. 7th ed. Philadelphia: Lippincott; 2000:345351.

49. Choudhury A, Lip G. Exercise and hypertension. J 
Hum Hypertens. 2005;19(8):585-588. doi:10.1038/ sj.jhh.1001851.

50. Marwick TH, Hordern MD, Miller T, et al. Exercise training for type 2 diabetes mellitus impact on cardiovascular risk: a scientific statement from the American Heart Association. Circulation. 2009;119(25):3244-3262. doi:10.1161/ CIRCULATIONAHA.109.192521

51. Kianbakht S, Khalighi-Sigaroodi F, Dabaghian FH. Improved glycemic control in patients with advanced type 2 diabetes mellitus taking Urtica dioica leaf extract: a randomized double-blind placebo-controlled clinical trial. Clin Lab. 2012;59(9-10):1071-1076. doi:10.7754/Clin. Lab.2012.121019.

52. Testai L, Chericoni S, Calderone V. Cardiovascular effects of Urtica dioica L. (Urticaceae) roots extracts: in vitro and in vivo pharmacological studies. J EthnopharmacoI. 2002;81(1):105-109. doi:10.1016/S0378-8741(02)00055-7.

53. Legssyer A, Ziyyat A, Mekhfi $\mathrm{H}$, et al. Cardiovascular effects of Urtica dioica L. in isolated rat heart and aorta.
Phytother Res. 2002;16(6):503-507. doi:10.1002/ptr.1087.

54. Taddei S, Virdis A, Mattei P, Natali A, Ferrannini E, Salvetti A. Effect of insulin on acetylcholine-induced vasodilation in normotensive subjects and patients with essential hypertension. Circulation. 1995;92(10):2911-2918. doi:10.1161/01.CIR.92.10.2911

55. Tarighat Esfanjani A, Namazi N, Bahrami A. Effect of hydro-alcoholic nettle extract on lipid profiles and blood pressure in type 2 diabetes patients. Iran J Endocrinol Metab. 2012;13(5):449-458.

56. Dizaye K, Alberzingi B, Sulaiman S. Renal and vascular studies of aqueous extract of Urtica dioica in rats and rabbits. Iraq J Vet Sci. 2013;27:25-31.

57. Tahri A, Yamani S, Legssyer A, et al. Acute diuretic, natriuretic and hypotensive effects of a continuous perfusion of aqueous extract of Urtica dioica in the rat. J Ethnopharmacol. 2000;73(1):95-100. doi:10.1016/S03788741(00)00270-1. 